\title{
Parametric and comparative study of spandrel beam effect on the punching shear strength of reinforced concrete flat plates
}

\author{
Jeung-Hwan Doh ${ }^{1}{ }^{\dagger}$, Hong Guan ${ }^{1}$ and Taewan $\mathrm{Kim}^{2}$ \\ ${ }^{1}$ Griffith School of Engineering, Griffith University Gold Coast Campus, Queensland 9726, Australia \\ ${ }^{2}$ Department of Civil, Architectural and Environmental System Engineering, Sungkyunkwan University, Suwon, \\ Republic of Korea
}

\begin{abstract}
SUMMARY
The safe and efficient construction of reinforced concrete flat plate systems requires an accurate, reliable and universally applicable procedure for the punching shear strength design. A nonlinear layered finite element method (LFEM) capable of analysing the punching shear strength of such system has been developed. Based on the LFEM, a parametric study is undertaken to evaluate some of the factors influencing punching shear strength of reinforced concrete flat palate with spandrel beams. This is done by varying the depth and the width of the spandrel beam while keeping other variables constant. The numerical results obtained by the LFEM are also compared with those predicted by the recommendations of the Australian Standard (AS3600-2009) and the Wollongong-Griffith (W-G) semi-empirical method. The results confirm that the Australian Standard is inadequate in predicting the punching shear strength at the corner and edge column connections of flat plates with spandrel beams or torsion strips. Copyright (C) 2010 John Wiley \& Sons, Ltd.
\end{abstract}

\section{INTRODUCTION}

The concrete flat plate system is a slab and column structure without drop panels and column capitals. Even though it requires expertise to design and analyse flat plate structure, it has more advantages over other forms of slab systems because of its pleasing appearance, which does not require beams and girders, hence eliminating the centre-to-centre floor spacing of a multi-storey building. In turn, the flat plate system provides more headroom and floor levels with the same building heights. As far as the construction is concerned, it requires only simple formwork that leads to a huge savings in construction materials and labour costs. In consequence, flat plates are widely used in multi-storey structures including office buildings and car parks.

In the design of concrete flat plates, the punching shear strength around the slab-column connections always poses a critical analysis problem. For corner and edge columns in particular, it is usually the focus of study due to the unbalance loading condition as well as the unsymmetrical stress distribution in these locations. Erroneous punching shear design has shown to lead to catastrophic failure because the failure is brittle. In view of these, punching shear strength and failure analysis of concrete flat plates has become one of the topics of intensive research in recent years by various concrete structure researchers worldwide.

The structural capacity of the concrete flat plate system can be enhanced by constructing spandrel beams along the edges of the slab. Note that a spandrel beam having the same depth as the adjacent slab is known as a torsion strip. However, this further complicates the already complex punching shear behaviour of the slab-column connections. The design of punching shear strength at slabcolumn-beam connections is currently carried out using some empirical or semi-empirical methods, which, amongst others, include the design code provisions. These methods involve approximations, which are not always reliable. Being empirical, their scopes of application are limited.

* Correspondence to: Jeung-Hwan Doh, Griffith School of Engineering, Griffith University, Gold Coast Campus, QLD, Australia, 4222

†E-mail: J.doh@griffith.edu.au 
The finite element method of analysis permits consideration of both material and geometric nonlinearities, as well as cracking and failure characteristic of reinforced concrete structures. It also permits the accurate analysis of the structural and material complexities such as concrete cracking, tension stiffening and nonlinear multi-axial material properties. Hence, the finite element method is able to overcome the deficiency of the empirical approaches. To an increasing degree, computational modelling of reinforced concrete structures is providing full and rigorous analysis of the complex behaviour of reinforced concrete structures. It also helps in the investigation of the complicated interactive effects of various structural parameters.

The punching shear strength and the accompanying failure mechanisms of reinforced concrete flat plates with spandrel beams is affected by various parameters including the depth and width of the spandrel beams and amount of their longitudinal steel reinforcement. Based on the nonlinear layered finite element method (LFEM) (Guan and Loo, 1997; Loo and Guan, 1997), a parametric study is undertaken in an effort to investigate the relationship between the punching shear strength and the overall dimensions of the spandrel beams. This investigation is conducted by varying the spandrel beam depth and width, while keeping other variables constant, such as overall depth of slab, column size, and compressive strength of concrete.

The numerical results are also compared with those predicted by the recent released Standard of Australia (AS3600-2009) and the W-G semi-empirical method. Based on the parametric and comparative study, a better understanding of the punching shear behaviour of flat plates with spandrel beams can be obtained and performance of the numerical method and the empirical approaches can be evaluated. In general, the punching shear strength increases with deeper and wider spandrel beam but only up to a certain limit.

\section{EXISTING PREDICTION METHODS AND THEIR PERFORMANCES}

\subsection{Codes of practice, AS3600}

For the punching shear strength analysis of flat plates with spandrel beams, empirical formulas are provided in the current Australian Standard AS3600-2009. The Australian Standard procedure is based heavily on the scale models of the edge panels of flat plate floors (Rangan and Hall, 1983). The formulas were derived with the aid of test results from flat plate models with torsional strips only. Further, for failure of corner connection, test results were available only for torsion strips without closed ties (i.e., free edges). Thus, the Australian Standard procedure grossly overestimates the punching shear strength of flat plates with spandrel beams, particularly for the case of the corner connections (Loo and Falamarki, 1992).

With crude approximations, both the American Concrete Institutes Code ACI 318-08 and the British Standard BS 8110-1997 are considered simplistic in that some important factors are neglected in their respective formulas. Hence, the effects of spandrel beam on the punching shear strength cannot be accounted for in their procedures. This, in turn, greatly limits the applications of these two national codes.

\subsection{W-G semi-empirical method}

Based on a series of half-scale model test results, set of explicit formulas (referred to herein as the W-G method) was developed by Loo and Falamaki (1992). The method is applicable to flat plates with either spandrel beams or torsion strips. The approach takes full account of the following important parameters and effects that were neglected or omitted in the other previously available methods: the slab-restraining factor is not a constant but a function of the strength of the spandrel beam; the distribution of shear force around the critical perimeter is not uniform but a function of the slab reinforcement ratio, clear span of the slab and the size of the spandrel beam in relation to the slab; the interaction of torsion, shear and moment in the spandrel beam (Falamaki and Loo. 1992).

With this approach, the punching shear strength at the corner and edge column connections can be determined. The W-G method takes full account of the important parameters and effects that are 


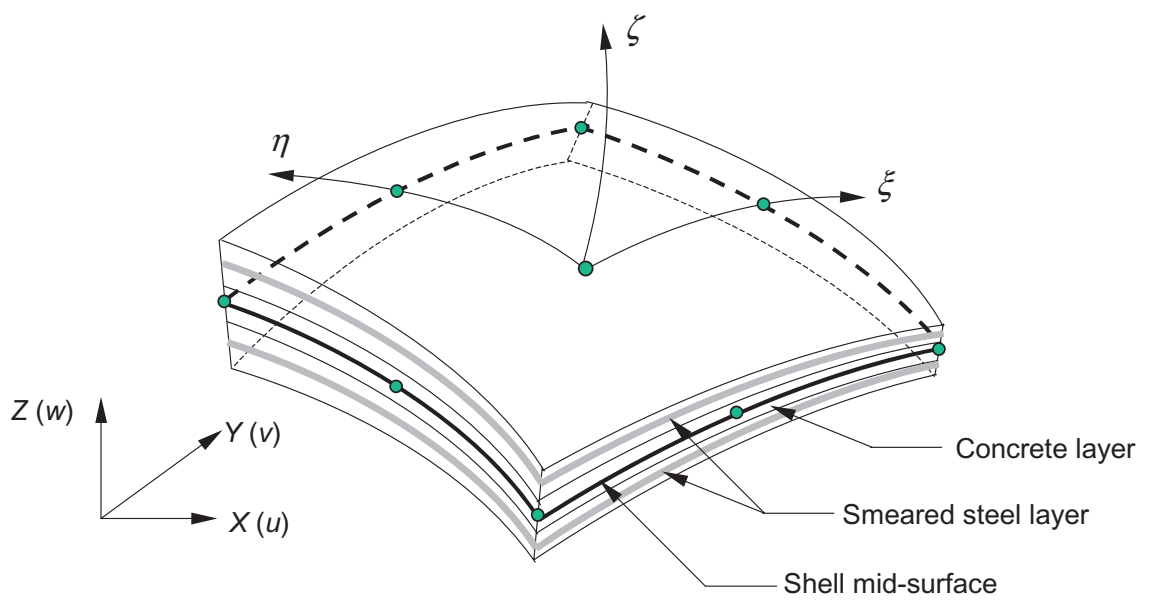

Figure 1. Concrete and steel layers.

omitted in the three national code methods. Although the formulas in the W-G approach is still semiempirical in nature, they are superior to those adopted in the code methods.

\subsection{Nonlinear LFEM}

For a rigorous cracking and failure analysis of reinforced concrete flat plates, a nonlinear LFEM has been developed by Guan and Loo (1997a, 1997b). Figure 1 illustrates the concept of the degenerate shell element encompassing concrete and smeared steel layers. Elements of this type was used in the LFEM where a smeared crack approach was adopted to model cracked concrete and a strain-hardening plasticity approach was employed to model concrete compressive behaviour. The effect of the tensionstiffening and the deterioration of shear stiffness were also considered after cracking of concrete. The contribution of the smeared reinforcing steels having elasto-plastic behaviour was added to that of concrete to form the total material constitutive matrix. With the shell element assumption, the transverse shear deformation can be accounted for which is crucial for punching shear analysis (Loo and Guan, 1997).

The LFEM is capable of solving three-dimensional problems of reinforced concrete structures and of analysing both flexural and shear cracking up to failure. In addition to the prediction of punching shear strength, the method is also capable of determining the load-deflection response, the ultimate load capacity, the deformation shape and the cracking patterns of the flat plates. It is considered far superior than the code methods and existing empirical approaches where only the punching shear strength can be predicted.

\subsection{Performances of the existing methods}

Based on the test results from fifteen half-scale reinforced concrete flat plate models (Falamaki and Loo, 1992), a series of comparative studies (Chiang and Loo, 1993; Loo and Guan, 1997) were carried out on the relative performance of the W-G method, the LFEM and the procedures recommended in three major codes of practice, viz. the Australian Standard, the British Standard and the ACI Code. The applicability accuracy and reliability of these methods were also reviewed. Note that both the ACI and the British recommendations are limited only to flat plates with torsion strips.

The main findings of the comparative studies are summarized below:

(1) For reinforced concrete flat plates without spandrel beams, unsafe results are given by the ACI approach. The British Standard procedure, on the other hand, overestimates the strengths of the models.

(2) For the corner-column connections in flat plates with spandrel beams, the predicted strength values by the Australian Standard can be many times more than the measured values for 
reinforced system. These are, of course, grossly unsafe results and must be a concern to all structural engineers.

(3) The W-G method provides consistent and accurate punching shear strength predictions for all the single- and multi-column models.

(4) The LFEM is able to predict, with very good accuracy, the punching shear strength for reinforced concrete flat plates with either spandrel beams or torsion strips.

(5) While the semi-empirical W-G method for reinforced concrete flat plates is generally accurate in predicting the punching shear strength, its applications are limited as it lacks the sophistication and all-encompassing capabilities of the LFEM.

\section{MODEL STRUCTURES}

\subsection{Flat plate model}

A $30 \times 26 \mathrm{~m}$ flat plate structure is considered in this study. The structure is supported by 6 internal columns, 4 corner columns and 10 edge columns. The plan view of the structure is shown in Figure 2. It consists of 12 rectangular panels, the smallest is $7 \times 8.5 \mathrm{~m}$ in plan and the largest is $8 \times 9 \mathrm{~m}$. Spandrel beams are located along the free edges of the slab in the $X$-direction. The use of spandrel beams provides extra strength in the slab-column connections and resists all horizontal forces caused by wind and earthquake loadings.

A typical cross-sectional view of slab and spandrel beam is shown in Figure 3. The overall slab thickness, $D_{s}$, is $250 \mathrm{~mm}$. Two layers of flexural reinforcement of Y16 at $250 \mathrm{~mm}$ centre-to-centre spacing running along the $X$ - and $Y$-directions are placed near the top and bottom surfaces, respectively. At corner, edge and internal column positions, additional top bars are provided to resist the larger negative bending moment at slab-column connections. The details of the slab reinforcement and the additional top steel bars are summarized in Table 1. Also included in the table is the arrangement of longitudinal and transverse reinforcements in the spandrel beam. Note that the slab was designed to ensure that it fails in punching shear.

Concrete with $32 \mathrm{MPa}$ compressive strength is used with $25 \mathrm{~mm}$ cover to both slab and spandrel beam reinforcements. The concrete and steel material properties are detailed in Table 2.

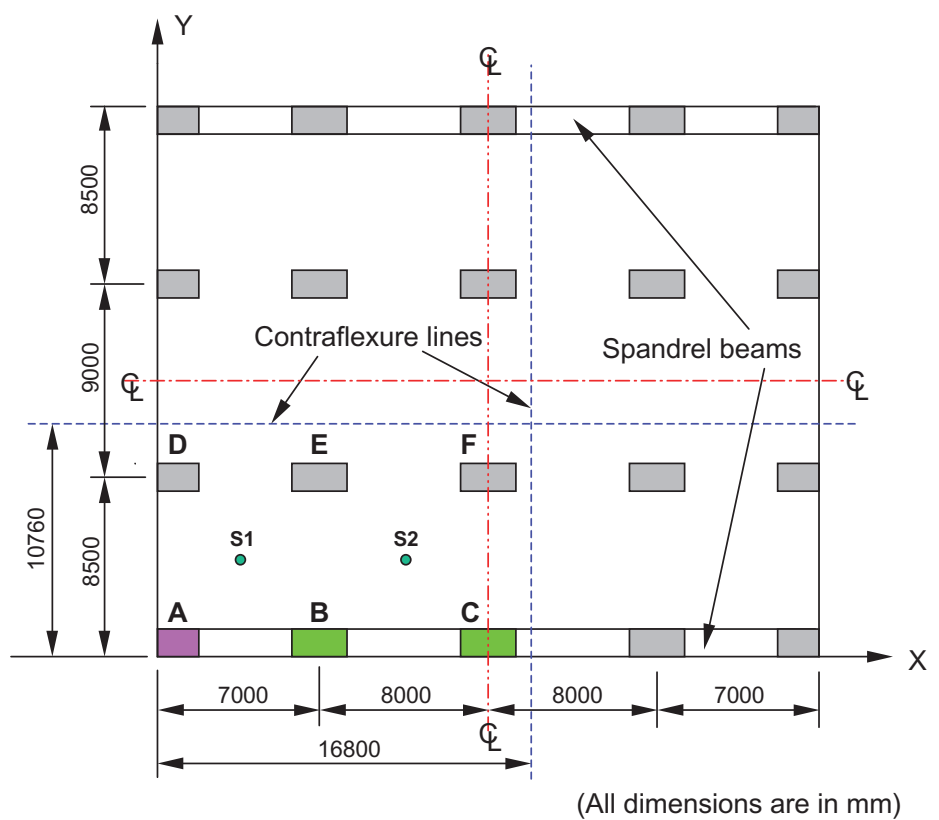

Figure 2. Plan view of the flat plate model. 


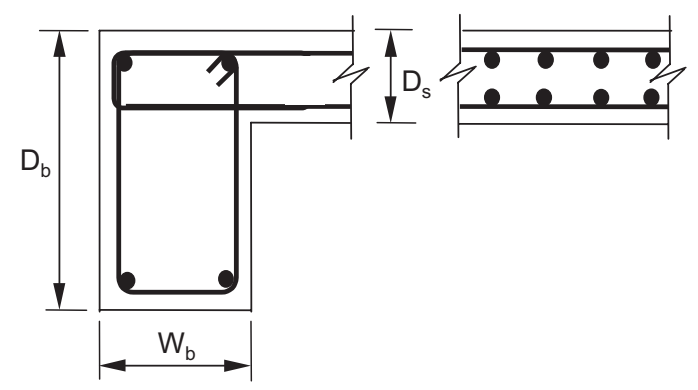

Figure 3. Spandrel beam and slab dimensions.

Table 1. Reinforcement details of slab and spandrel beam.

\begin{tabular}{|c|c|c|c|}
\hline \multicolumn{3}{|c|}{ Slab steel } & \multirow{3}{*}{$\begin{array}{l}\text { Spandrel steel } \\
\text { Y16 mm at top and bottom } \\
\text { along the } X \text {-direction, } \\
\text { R10 closed ties } \\
@ 100 \mathrm{~mm}\end{array}$} \\
\hline Region & Top steel & Bottom steel & \\
\hline Overall slab & $\begin{array}{l}\text { Y16@250 mm along the } X \text { - and } \\
Y \text {-directions }\end{array}$ & $\begin{array}{l}\text { Y16@250 mm along the } \\
X \text { - and } Y \text {-directions }\end{array}$ & \\
\hline Corner columns & $\begin{array}{l}\text { Y16@240 mm along } X \text {-direction } \\
\text { Y16@220 } \mathrm{mm} \text { along } Y \text {-direction }\end{array}$ & & \\
\hline Edge columns & $\begin{array}{l}\text { Y16@240 mm along } X \text {-direction } \\
\text { Y16@260 mm along } Y \text {-direction }\end{array}$ & & \\
\hline Interior columns & $\begin{array}{l}\text { Y16@100 mm along } X \text {-direction } \\
\text { Y16@60 mm along } Y \text {-direction }\end{array}$ & & \\
\hline
\end{tabular}

Table 2. Material properties.

\begin{tabular}{lclr}
\hline & Concrete & & Steel \\
\hline Young's modulus $E c(\mathrm{MPa})$ & 29970 & Young's modulus $E_{s}(\mathrm{MPa})$ & 231745 \\
Poisson's ratio $v$ & $0 \cdot 15$ & Yield stress $f y(\mathrm{MPa})$ & 570 \\
Ultimate compressive strength $f^{\prime} c(\mathrm{MPa})$ & 32 & & \\
Ultimate tensile strength $f^{\prime} t(\mathrm{MPa})$ & $2 \cdot 371$ & & \\
\hline
\end{tabular}

The entire slab has two axes of symmetry taking into account both its geometry and material properties. Owing to this feature, only two panels ABED and BCFE are considered in this study. This is shown as the area enclosed by the free edges of the slab and the two lines coincide with the contraflexure lines. Consequently, the analysis of the entire structure is reduced to a simplified analysis of two adjacent and representative panels. This simplification can significantly minimize the unnecessary computational effort for repetitive analysis.

The dimensions of Columns A, B and C are $400 \times 500 \mathrm{~mm}, 600 \times 500 \mathrm{~mm}$ and $800 \times 500 \mathrm{~mm}$ respectively; while the dimensions of Columns D, E and F are identical, being $400 \times 800 \mathrm{~mm}$. Figure 2 also shows tow typical points S1 and S2 for the two panels, respectively, where the deflection of the slab is monitored.

In the parametric study, a series of 14 flat plate models are designed, in which the depths and widths of spandrel beams vary while keeping other material and geometric properties constant. This methodology allows for the evaluation of spandrel beam effects on the punching shear strength. In the study, the depths of the spandrel beams are allowed to vary from 250 to $600 \mathrm{~mm}$ at $50 \mathrm{~mm}$ intervals. This results in eight models that are designated as D250 to D600. Model D250 has only torsion strip along its edge. The widths of the spandrel beams are considered to vary from 300 to $800 \mathrm{~mm}$ at $100 \mathrm{~mm}$ intervals, and the resulting six models are designated as W300 to W800. Note that when the depths and widths of the spandrel beams vary, other structural and material parameters of the fourteen models are kept the same. Details of the spandrel beam dimensions are presented in Tables 3 and 4, respectively, for models with varying depth and width. Variables $W_{b}$ and $D_{b}$ can be found in Figure 3. 
Table 3. Dimensions of the spandrel beams for models with varying depth.

\begin{tabular}{lccccccrr}
\hline Model & D250 & D300 & D350 & D400 & D450 & D500 & D550 & D600 \\
\hline$W_{b}(\mathrm{~mm})$ & 500 & 500 & 500 & 500 & 500 & 500 & 500 & 500 \\
$D_{b}(\mathrm{~mm})$ & 250 & 300 & 350 & 400 & 450 & 500 & 550 & 600 \\
\hline
\end{tabular}

Table 4. Dimensions of the spandrel beams for models with varying width.

\begin{tabular}{lcccccc}
\hline Model & W300 & W400 & W500 & W600 & W700 & W800 \\
\hline$W_{b}(\mathrm{~mm})$ & 300 & 400 & 500 & 600 & 700 & 800 \\
$D_{b}(\mathrm{~mm})$ & 350 & 350 & 350 & 350 & 350 & 350 \\
\hline
\end{tabular}

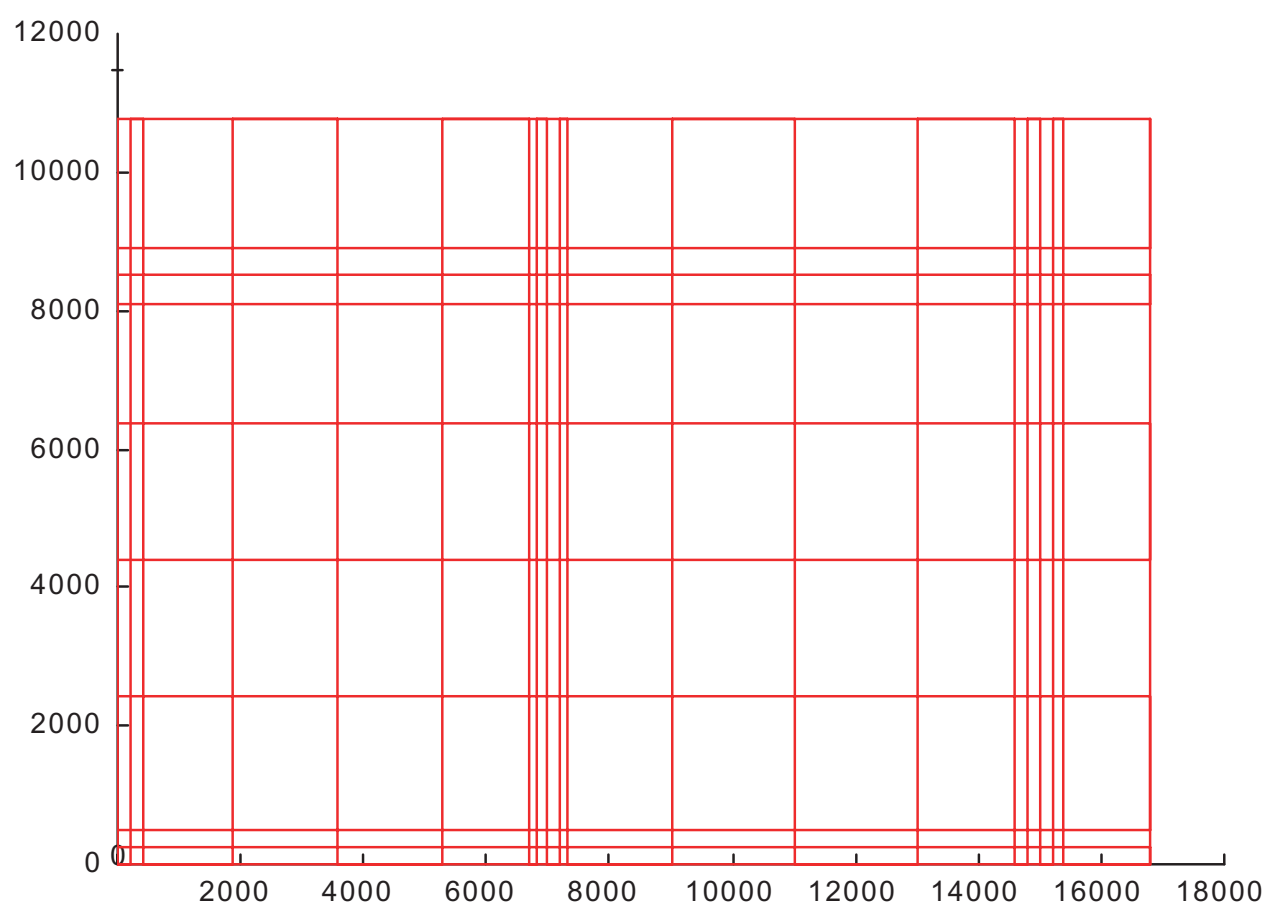

Figure 4. Typical Finite element mesh generation for Model D350.

\subsection{Finite element model}

All 14 models are simulated numerically using the LFEM. The two panels are modelled using a $19 \times 9$ mesh scheme and the panel dimensions are $10760 \mathrm{~mm} \times 16800 \mathrm{~mm}$ in which all 14 slabs are modelled from spandrel beam to contraflexure lines as shown in Figure 2. Each element is subdivided into eight concrete layers of different thickness. The thinnest concrete layers are at the bottom and top of the element. The layer thickness gradually increases towards the element mid-surface. The reinforcement meshes for both slab and spandrel beam is expressed in terms of the normalized curvilinear coordinate. This permits the variation of the layer thickness with non-prismatic cross sections for beams and slab structures. This simplifies the input data for steel reinforcement. With this technique, the top and bottom reinforcement meshes are simulated by four (smeared) steel layers.

All six columns are $3.0 \mathrm{~m}$ high. In the analysis, however, the column height is taken from the slab soffit to the theoretical contraflexural point. It is necessary to double the stiffness of each column to resist twice the moments as the columns above the slab are omitted. All column supports are taken to be hinged and free to rotate about the $X$ - and $Y$-axes (see Figure 2). As a typical example, the finite element mesh for Model D350 is presented in Figure 4. 
Table 5. Additional material properties used for numerical analysis.

\begin{tabular}{lllr}
\hline & Concrete & Steel \\
\hline Ultimate compressive strain $\varepsilon$ & 0.004 & Steel orientation (1) $\theta_{x 1}$ & 1.5708 \\
Tension stiffening coefficient $\alpha$ & 0.6 & Steel orientation (2) $\theta_{x 2}$ & 0 \\
Tension stiffening coefficient $\varepsilon_{m}$ & 0.002 & & \\
\hline
\end{tabular}

Table 6. Shear strength for models with varying depth and width of spandrel beam.

\begin{tabular}{lcc}
\hline Model & Shear strength $V_{b}(\mathrm{kN})$ & Collapse load $(\mathrm{kPa})$ \\
\hline D250 & $281 \cdot 51$ & 30 \\
D300 & $336 \cdot 67$ & 35 \\
D350 & $394 \cdot 12$ & 40 \\
D400 & $444 \cdot 24$ & 35 \\
D450 & $498 \cdot 77$ & 30 \\
D500 & $552 \cdot 42$ & 30 \\
D550 & $605 \cdot 30$ & 30 \\
D600 & $647 \cdot 44$ & 30 \\
W300 & $331 \cdot 89$ & 30 \\
W400 & $366 \cdot 15$ & 40 \\
W500 & $394 \cdot 12$ & 40 \\
W600 & $413 \cdot 05$ & 41 \\
W700 & $431 \cdot 45$ & 46 \\
W800 & $444 \cdot 03$ & 50 \\
\hline
\end{tabular}

An incremental and iterative procedure is used to obtain the nonlinear solution. With the LFEM, the nonlinear behaviour caused by both material and geometric nonlinearities can be reproduced. As required by the program developed on the basis of LFEM, Table 5 summarizes the additional material properties for both concrete and steel. A uniformly distributed area load is applied on top of the slab except for the column regions. The total load applied is divided into a number of steps. Larger increments are applied at the initial stages followed by gradually decreased increments up to the failure load.

\section{PARAMETRIC AND COMPARATIVE STUDY}

\subsection{Punching shear strength}

Punching shear strength is the net ultimate reaction at the column contraflexural point. The punching shear strength results $\left(V_{p}\right)$ using the LFEM are compared with the predictions due to the Australian Standard procedure and the semi-empirical W-G method. These comparison as well as the corresponding collapse loads predicted by the LFEM are presented in Tables 6-8, for models with varying depth and width of the spandrel beams. The shear strengths of the beams calculated using the Australian Standard formulas are also included in Tables 7 and 8. For each method, the punching shear strengths at corner Columns A and B and edge Column C are tabulated. This study focuses on the prediction of the punching shear strength of flat plate structures based on which the advantages and limitations of each method can be evaluated.

The punching shear strengths predicted by the Australian Standard and the W-G method increase with deeper spandrel beams (see Table 7). The results due to the LFEM, on the other hand, show that punching shear strengths at all column positions increase with deeper spandrel beams up to a certain limit. When the depth of the beams goes beyond $400 \mathrm{~mm}$, the punching shear strength decreases. Similar phenomenon is also found for the collapse load as shown in Table 6. This is because the total weight of the model gradually increases with deeper spandrel beam and as a result, the slabs fail sooner. 


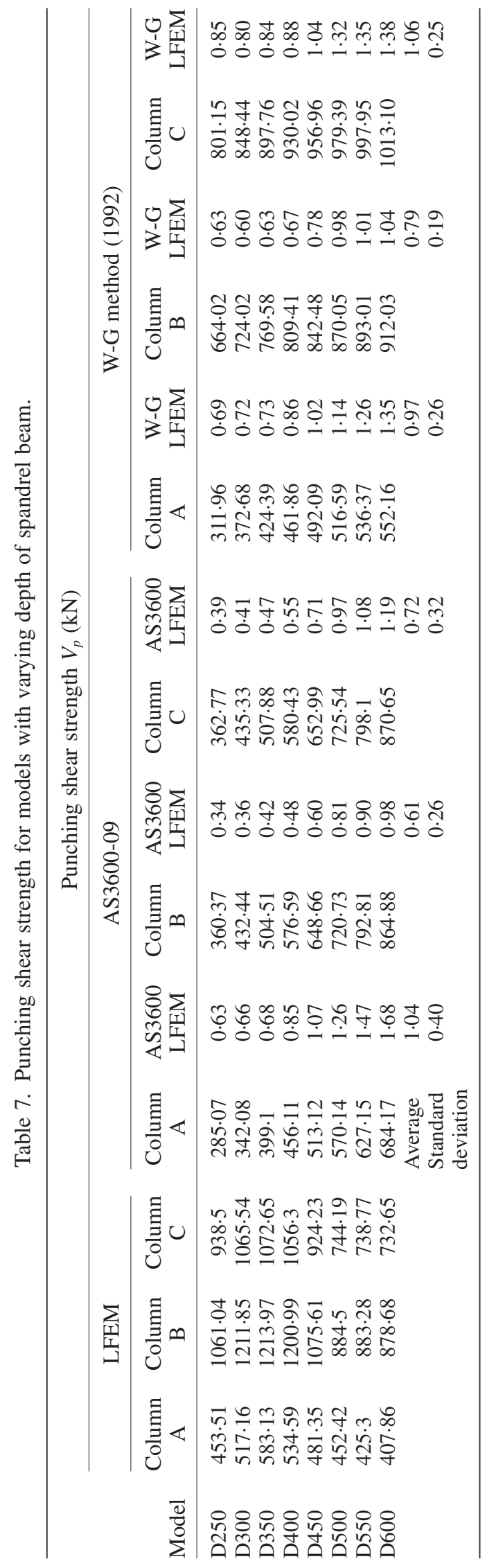




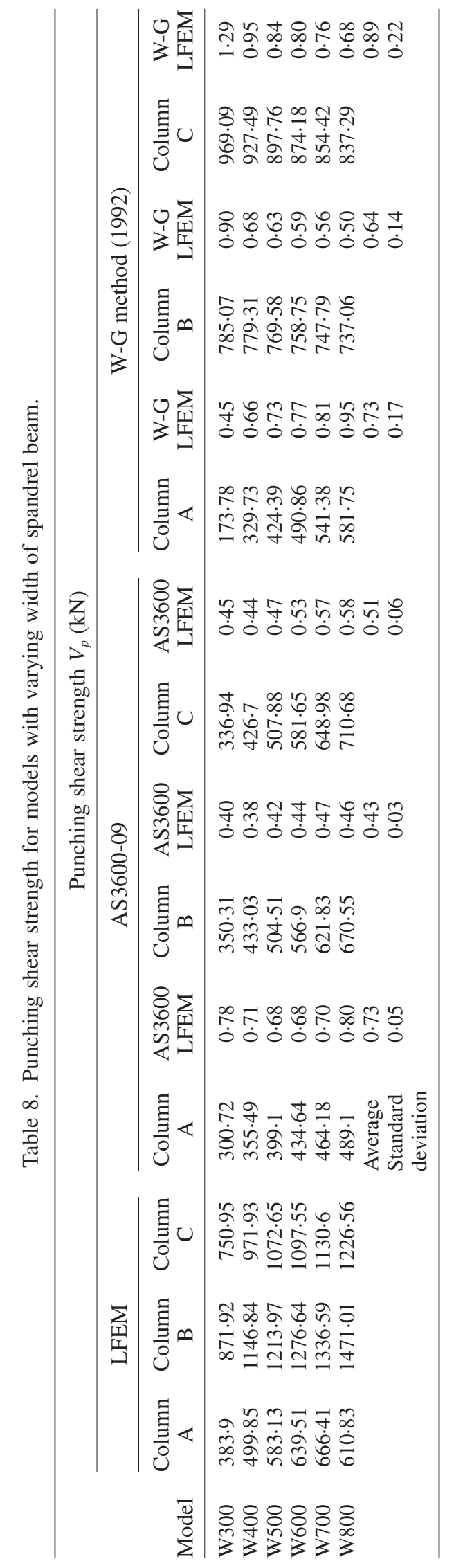




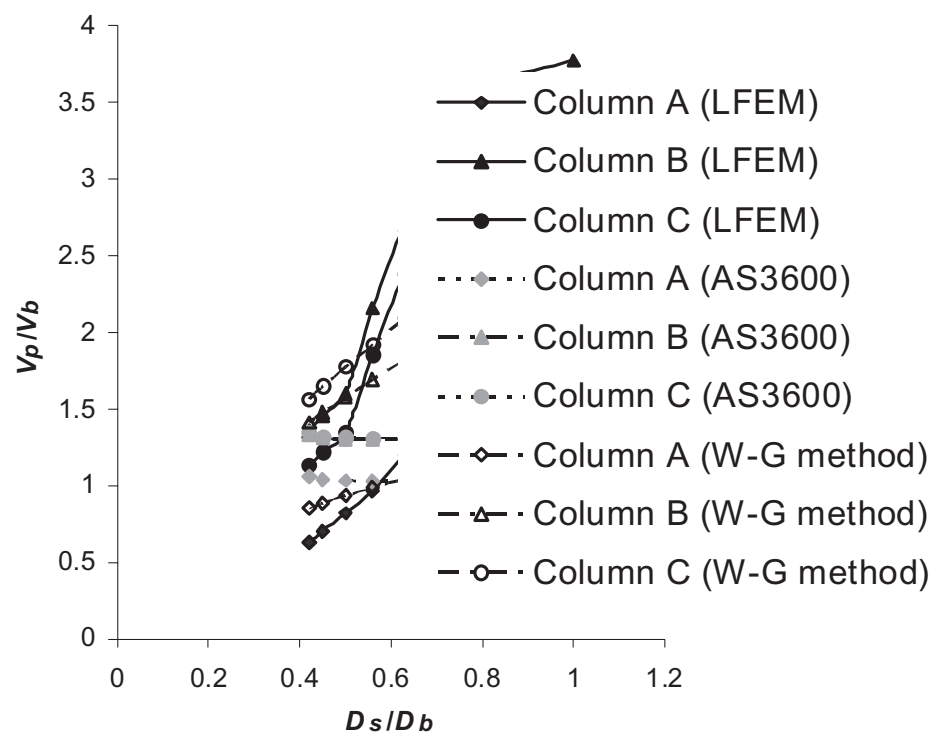

Figure 5. $V_{p} / V_{b}$ versus $D_{s} / D_{b}$.

When the width of spandrel beams increases, the punching shear strength $V_{p}$ due to the LFEM increases accordingly. This agrees well with the Australian Standard prediction and the W-G method (see Table 8). Also, the collapse load increases with wider beams. It is further observed in Table 6 that the shear strength $V_{b}$ of the beam increases with deeper and wider spandrel beams.

Also indicated in Tables 7 and 8, a comparison study is conducted and the results of the finite element method and W-G method are closer to each other when varying the spandrel beam depths. The results indicate that the ratios of the LFEM and W-G method at Column A, B and C varied from 0.63 to 1.38 with a mean of $0.97,0.79$ and 1.06 , and a standard deviation of $0.26,0.19$ and 0.25 , respectively. When varying the width of spandrel beam, the ratios of the LFEM and W-G approach are slightly lower than the ratio obtained from varying the depth of the beam.

However, the results from the Australian Standard predictions show that the ratio decreases slightly with deeper spandrel beam. Also, larger columns show greater discrepancies between the LFEM and the Australian Standard predictions. As a result, the Australian Standard procedure fails to achieve the same level of accuracy due to the approximations involved in using empirical formulas created from half scale model tests results. Hence, the results obtained from AS3600 are less conservative than the W-G approach.

The punching shear strength results are presented in non-dimensional format. For the eight models with varying depth, this is done by considering the ratio of the punching shear strength of the slab and the shear strength of the beam $\left(V_{l} / V_{b}\right)$, against the slab and beam thickness ratio $\left(D / D_{b}\right)$. Presented in Figure 5 are the $\left(V_{I} / V_{b}\right)$ versus $\left(D / D_{b}\right)$ plots for Columns A, B and C due to the three methods. As can be seen, for all columns, that the $\left(V_{f} / V_{b}\right)$ versus $\left(D / D_{b}\right)$ plots due to the LFEM and the W-G method increase with a decrease in spandrel beam depth. The Australian standard predictions, on the other hand, produce slightly decreased curves. In addition, for Columns B and C, both results of LFEM and the W-G method are closer to each other, whereas the Australian standard predictions are rather apart. It may be further noticed that, the Australian standard prediction does not appear to be sensitive when the depth of spandrel beam varies. This is because when using the AS3600 formulas, the effect of $D_{b}$ is cancelled out in determining $V_{I} / V_{b}$, as both $V_{p}$ and $V_{b}$ are functions of $D_{b}$ in such formulas.

For the six models with varying width, the ratio of punching shear strength of the slab and the shear strength of beam $\left(V_{I} / V_{b}\right)$ is plotted against the spandrel beam width $W_{b}$. This is presented in Figure 6 for Columns A, B and $\mathrm{C}$ due to the three methods.

It can be seen that for corner Column $\mathrm{A}$, the $V_{I} / V_{b}$ versus $W_{b}$ curves resulted by the three methods are fairly close to each other. For the two edge columns (Column B and C), the LFEM and 


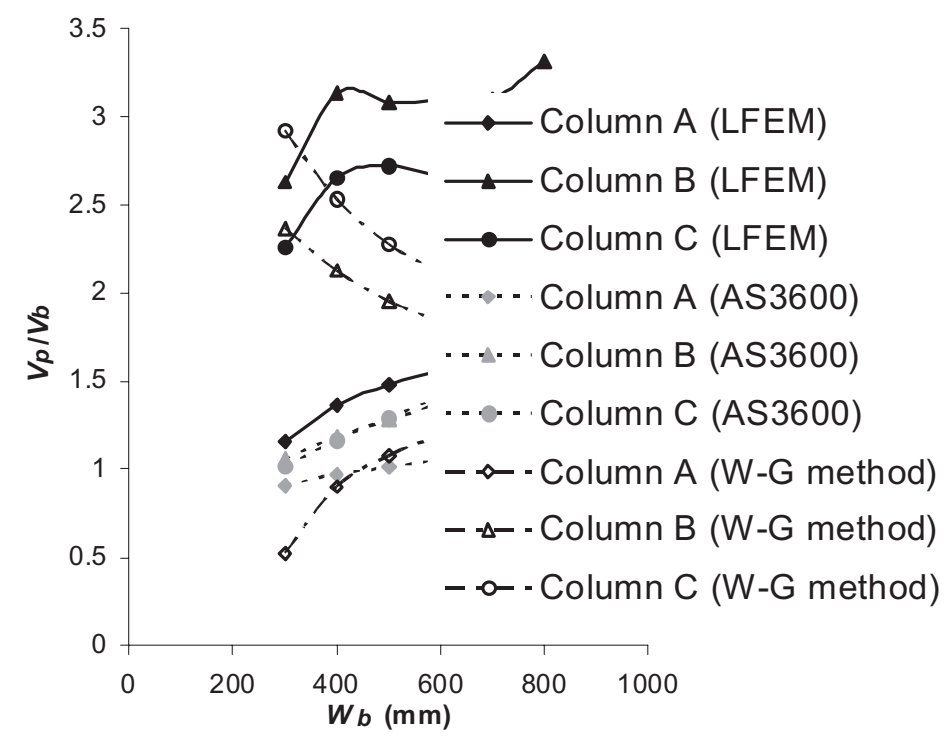

Figure $6 . V_{p} / V_{b}$ versus $W_{b}$.

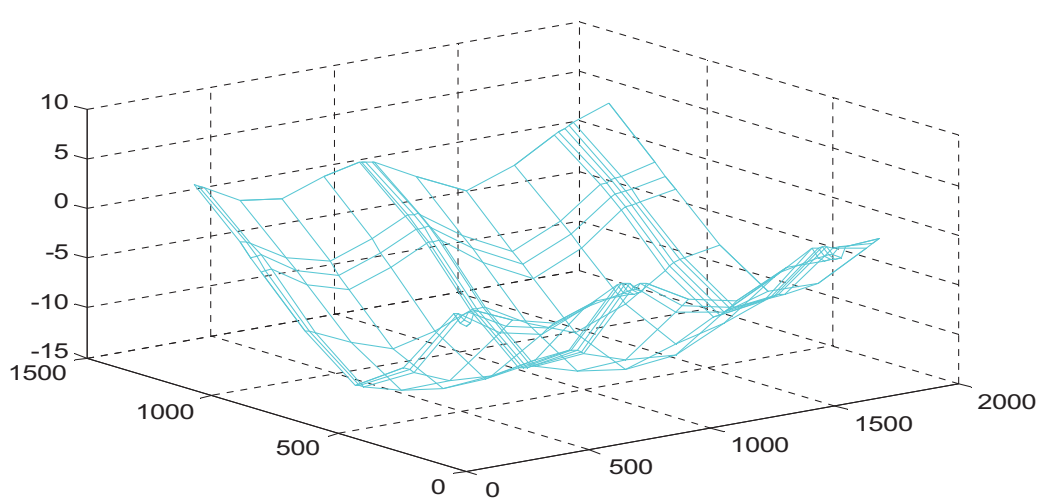

Figure 7. Deformed shape of Model D350.

the Australian Standard predictions produce increasing linearly, whereas the W-G method yields decreasing curves. Even though, the performance of the W-G method is considered satisfactory because its predictions are situated in between those of LFEM for narrower spandrel beams and of Australian Standard for wider beams.

\subsection{Deflection response}

A typical example of the exaggerated deformed shape for Model D350 at ultimate stage is presented in Figure 7. It can be visualized that the maximum deflection occurs at the centre of each panel. This is due to the support condition of the structure where the columns are fixed and restrained at their contraflexure point. One of the advantages of the LFEM is that it can predict the deformation of the structure and therefore can forecast the worst scenario the slab can encounter. This helps the designer of this type of structure to make good judgment on how his design will act during the life of the slab before it will be built. It will also give visual information on how the slab behaves on different types of loading conditions.

Figure $8(\mathrm{a}, \mathrm{b})$ depicts the load-deflection responses for models with varying depth of spandrel beams. Those figures are plotted at points S1 and S2, respectively (see Figure 2). It can be noticed 


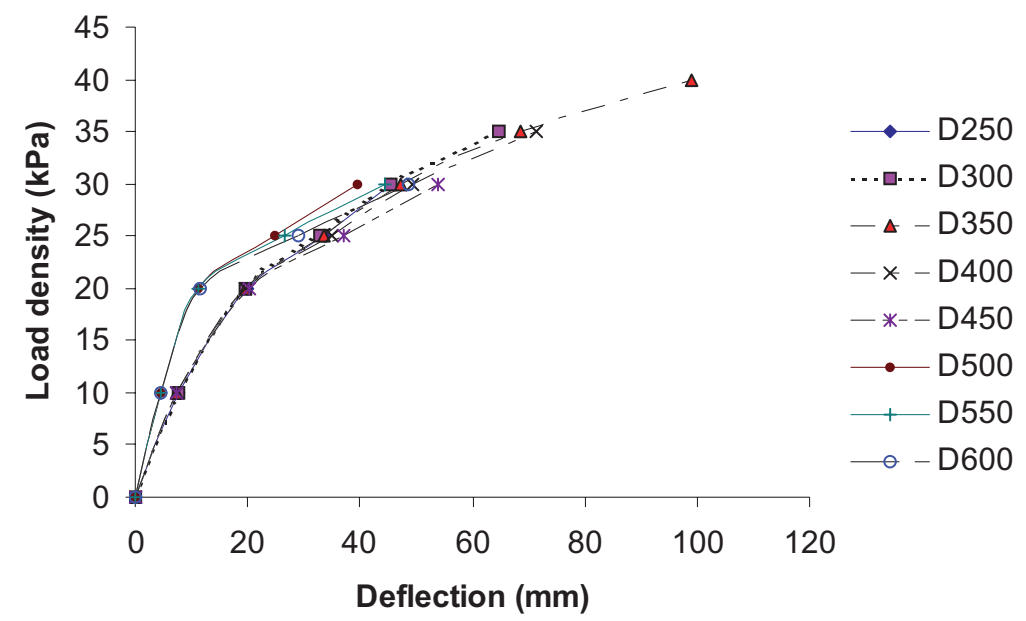

(a)

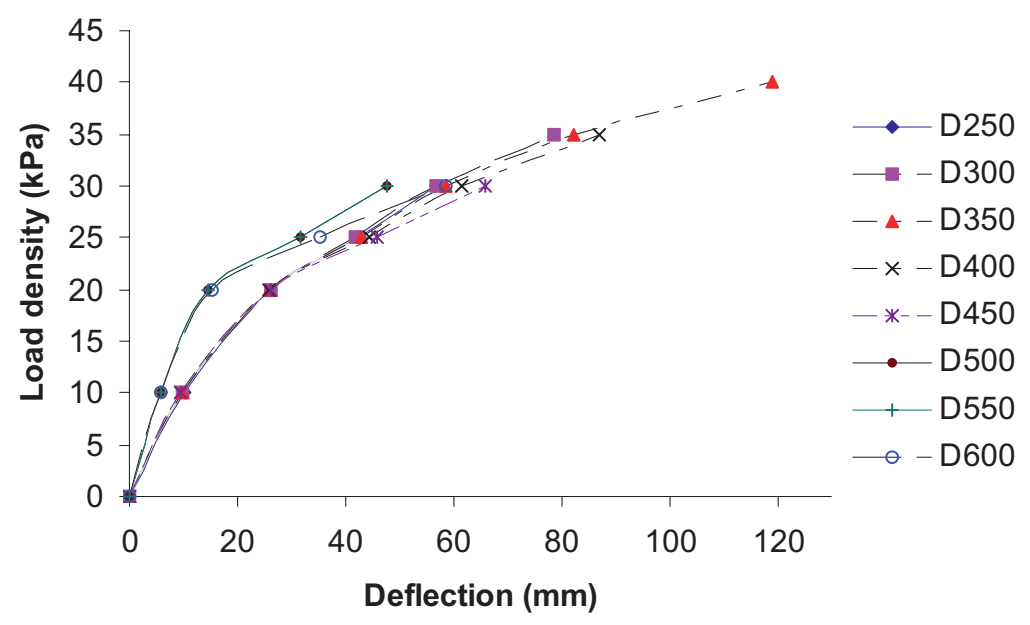

(b)

Figure 8. Load-deflection response for models with varying depth of spandrel beam: (a) at point $\mathrm{S} 1$; and (b) at point $\mathrm{S} 2$.

that at the same loading, the deflection at point S2 is higher than that at S1. For Model D350, in particular, the deflection at point $\mathrm{S} 1$ is $100 \mathrm{~mm}$ and $115 \mathrm{~mm}$ at point $\mathrm{S} 2$ at the same load density. This suggests that the edge panel (BCFE) deflects more than the corner panel (ABED). This is because the loading area of the edge panel is about 14\% larger as compared to that of the corner panel. It can also be noticed that the deeper the spandrel beam, the higher the load-carrying capacity of the slab. However, when the spandrel beam depth increases beyond $350 \mathrm{~mm}$, the load-carrying capacity of the slab gradually reduces to the same level as that of the slab with a torsion strip (D250). This is in accordance with the punching shear strength results where the load capacity increases with deeper spandrel beam but only within some boundary limits.

Figure 9(a, b) plots, at points S1 and S2, respectively, the load-deflection responses for models with varying width of spandrel beam. Again, for all models, the deflection at point S2 is larger than that at point S1. In general, the load-carrying capacity of the slab increases with wider spandrel beam, and the slab deflects more accordingly. It can be further noticed that the load-deflection responses are proportionally affected by changing the width of the spandrel beam. Whereas, for models with varying depth, the load-deflection responses follow almost the same trend except when the spandrel beams become too deep. 


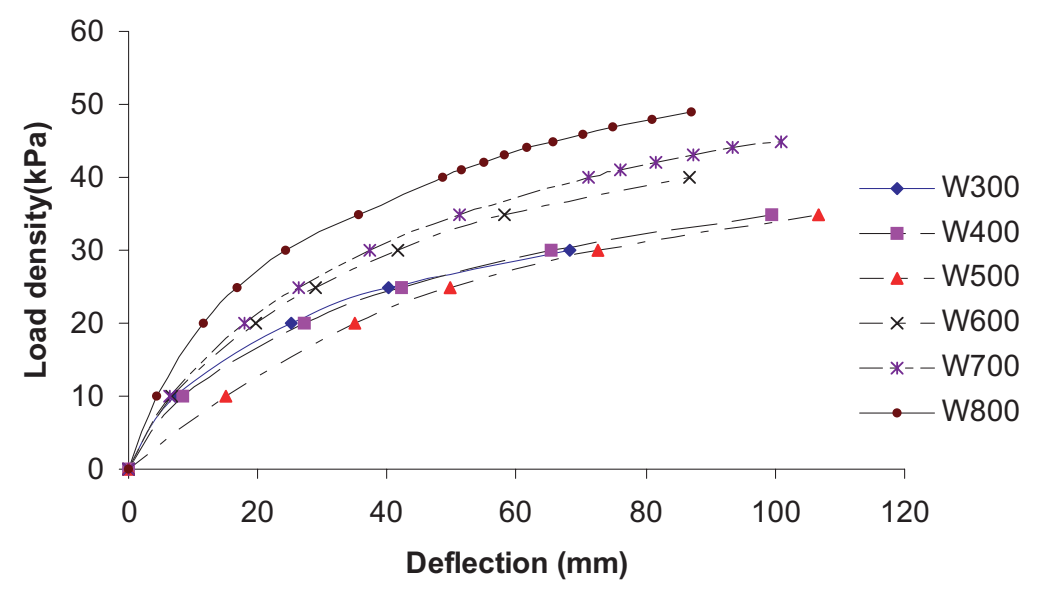

(a)

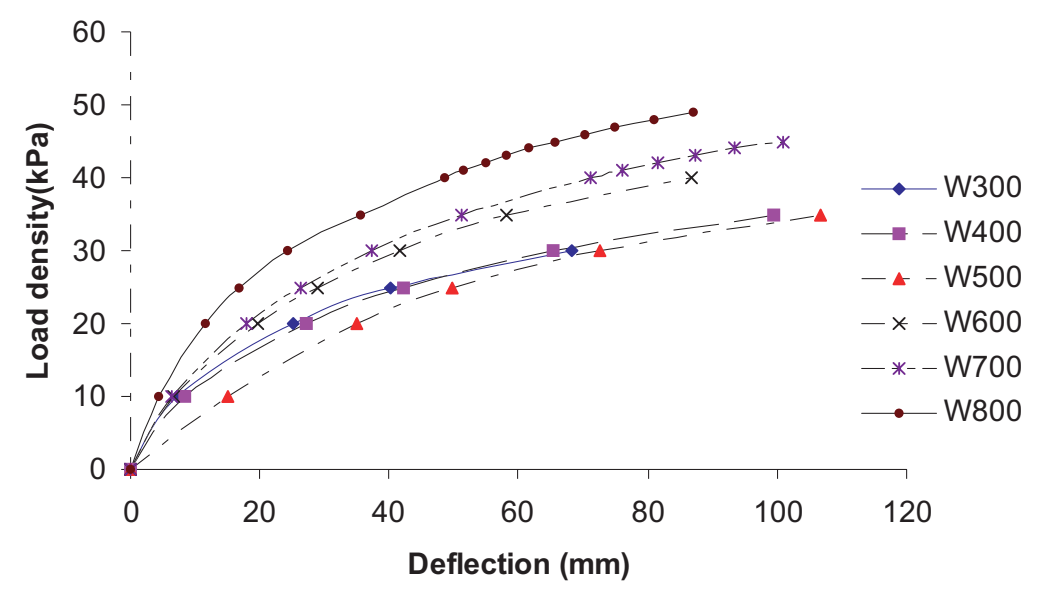

(b)

Figure 9. Load-deflection response for models with varying width of spandrel beam: (a) at point $\mathrm{S} 1$; and (b) at point $\mathrm{S} 2$.

\subsection{Cracking behaviour}

At the ultimate load, the analytical crack patterns generated by the LFEM are presented in Figures 10 and 11, selected models D400 and W400, respectively. For each model, the crack patterns at both bottom and top layers of the slab are displayed. The figures show that a large number of cracks appear at the bottom layer around middle strip region and at the top layer surrounding the column faces. The overall crack patterns for all models are similar except those in the spandrel beam region which is affected by its varying features.

It can also be visualized from the crack patterns for both models that a portion of the concrete around the column is similar to the frustum of a pyramid extending from the top to the bottom surfaces. With this occurrence the slab strength has lost at the final stage of loading and led to a punching shear failure.

\section{CONCLUSION}

A nonlinear layered finite element method for punching shear failure analysis is employed for the parametric and comparative study of a series of reinforced concrete plates with spandrel beams. In total, 14 flat plate models with different characteristics of spandrel beam are designed and 


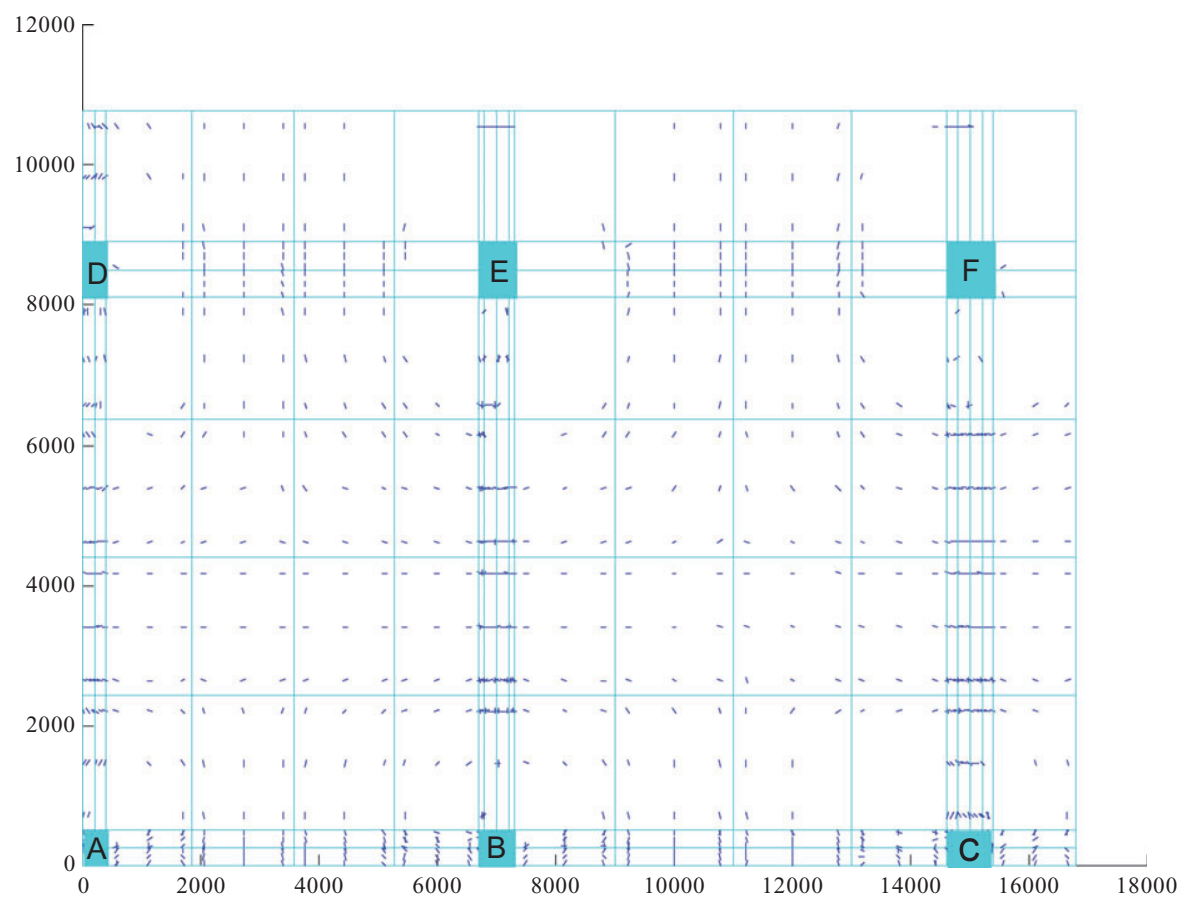

(a)

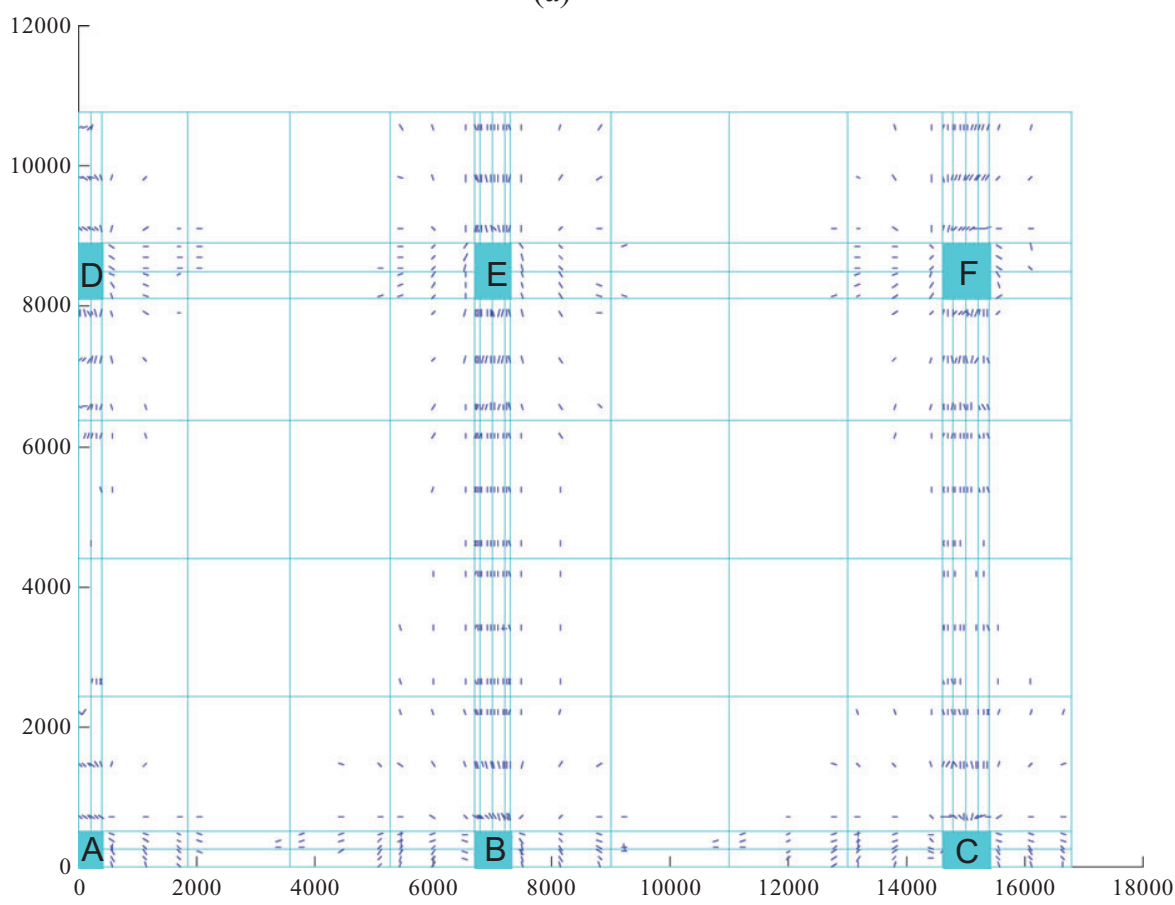

(b)

Figure 10. Crack pattern of Model D400: (a) bottom layer of slab; and (b) top layer of slab.

analysed. They include eight models with varying depth of spandrel beam and six with varying width. The numerical results are also compared with those due to the W-G semi-empirical method and the Australian Standard predictions. The numerical study indicates that, the punching shear strength, in general, increases with deeper and wider spandrel beam but only within some boundary limits. 


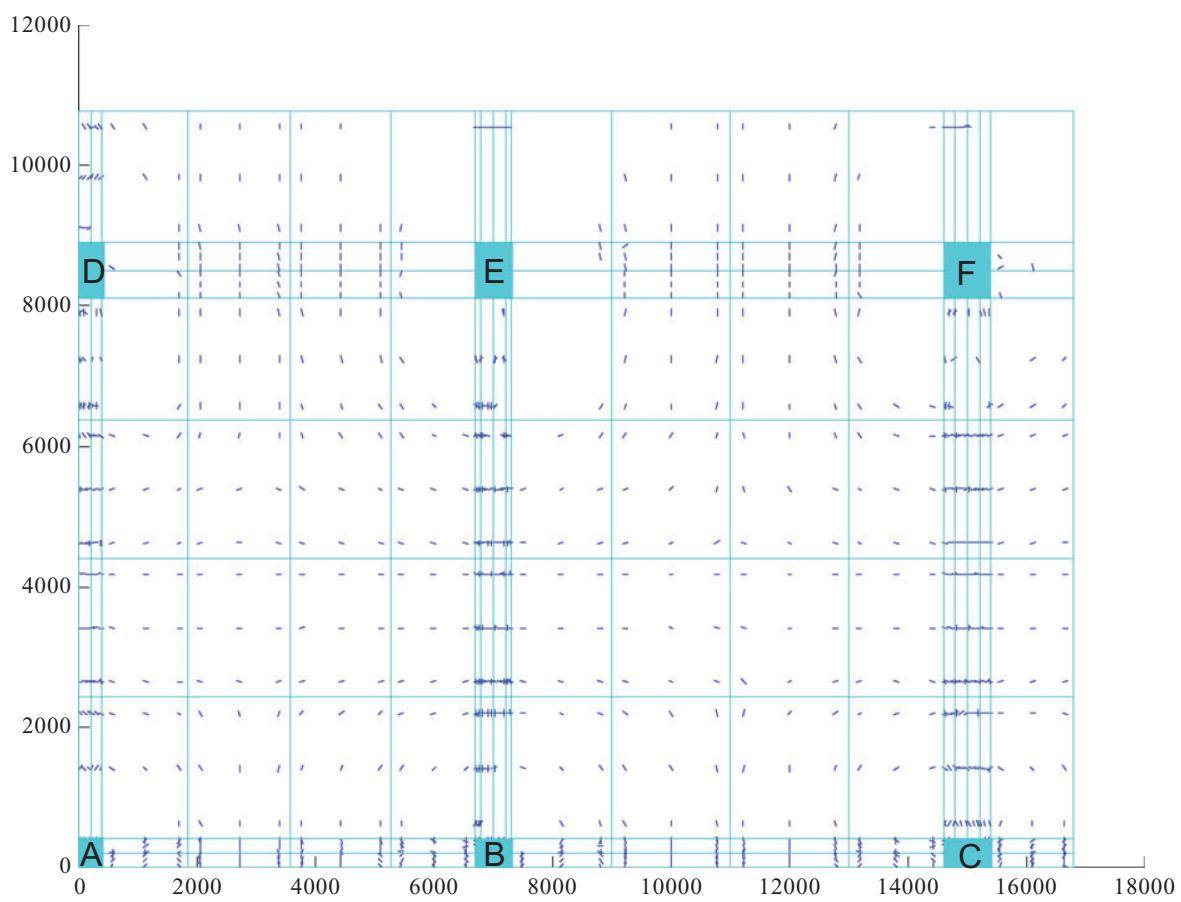

(a)

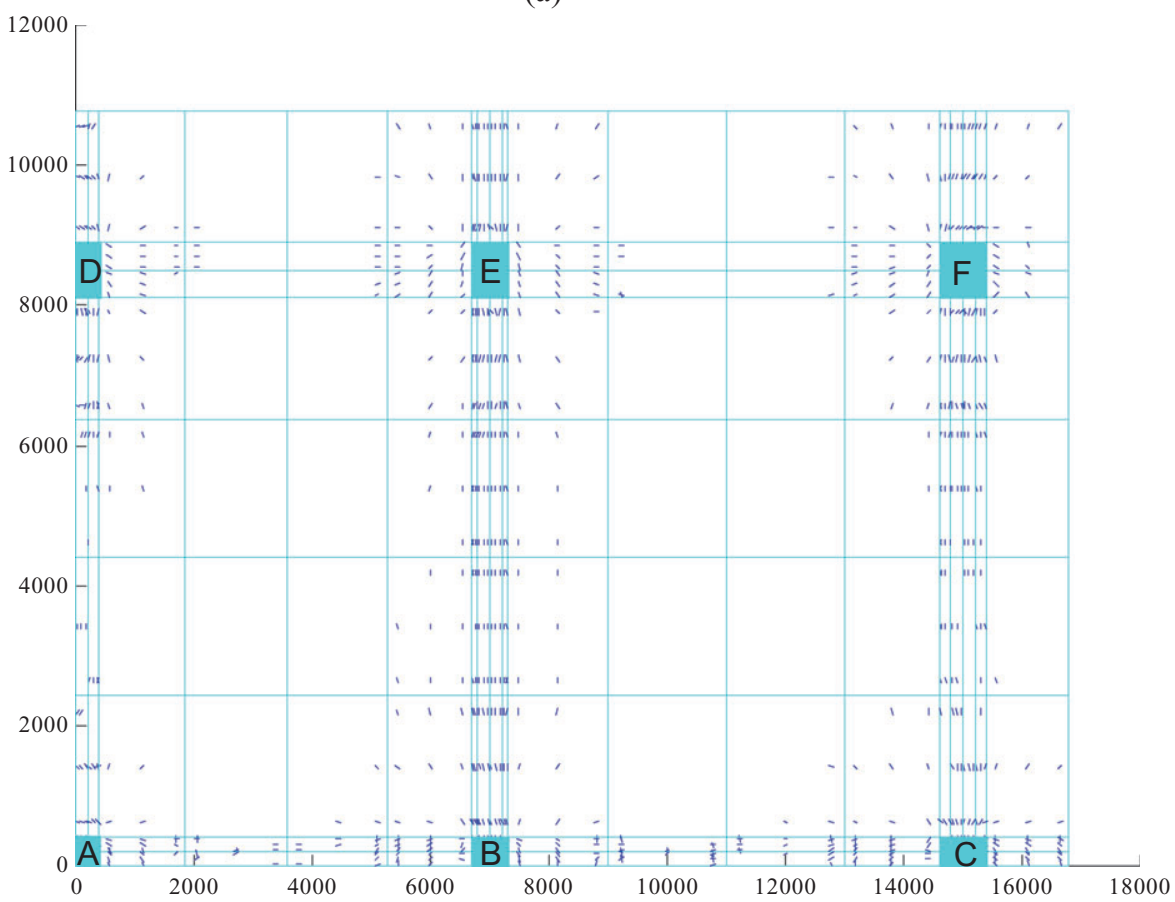

(b)

Figure 11. Crack pattern of Model W400: (a) bottom layer of slab; and (b) top layer of slab.

Based on the 14 model tests results, a parametric study is conducted that the results of the finite element method and Wollongong-Griffith method are closer to each other, however, the results from the Australian Standard predictions show that the ratio decreases slightly with deeper spandrel beam. Also, larger columns show greater discrepancies between the LFEM and the Australian Standard predictions. As a result, the Australian Standard procedure fails to achieve the same level of accuracy 
due to the approximations involved in using empirical formulas created from half scale model tests results.

\section{REFERENCES}

ACI318-08. 2008. Building Code Requirements for Structural Plain Concrete. American Concrete Institute: Detroit, MI.

BS8110-1997. 1997. Structural Use of Concrete Part I-Code of Practice for Design and Construction. British Standards Institution: London.

Chiang CL, Loo YC. 1993. Methods of punching shear strength analysis of reinforced concrete flat plates-a comparative study. International Journal of Structural Engineering and Mechanics 1(1): 75-86.

Falamaki M, Loo YC. 1992. Punching shear strength analysis of reinforced concrete flat plates with spandrel beams. ACI Structural Journal 89(3): 263-271.

Guan H, Loo YC. 1997a. Flexural and shear failure analysis of reinforced concrete slabs and flat plates. Advances in Structural Engineering 1(1): 71-85.

Guan H, Loo YC. 1997b Layered finite element method in cracking and failure analysis of rc beams and beam-column-slab connections. International Journal of Structural Engineering and Mechanics 5(5): 645-662.

Loo YC, Falamaki M. 1992. Punching shear tests of half-scale reinforced concrete flat-plate models with spandrel beams. ACI Structural Journal 89(4): 375-383.

Loo YC, Guan H. 1997. Cracking and punching shear failure analysis of RC flat plates. Journal of Structural Engineering, ASCE 123(10): 1321-1330.

Rangan BV, Hall AS. 1983. Moment and shear transfer between slab and column. ACI Structural Journal 80(3): 183-191.

Rangan BV. 1990. Punching shear design in the new Australian standard for concrete structures of reinforced. ACI Structural Journal 87(2): 140-144.

Standards Association of Australia (AS3600). 2009. AS3600-09: Concrete Structures. Standards Association of Australia: Sydney. 